\title{
A prospective study on the role of umbilical artery doppler velocimetry in the perinatal outcome of growth restricted fetuses
}

\author{
Sumathi R., Mercy R. Rodrigo*
}

Department of Obstetrics and Gynecology, Thoothukudi Government Medical College Hospital, Thoothukudi, Tamil Nadu, India

Received: 16 September 2019

Accepted: 25 October 2019

*Correspondence:

Dr. Mercy R. Rodrigo,

E-mail: mercyravi2003@gmail.com

Copyright: () the author(s), publisher and licensee Medip Academy. This is an open-access article distributed under the terms of the Creative Commons Attribution Non-Commercial License, which permits unrestricted non-commercial use, distribution, and reproduction in any medium, provided the original work is properly cited.

\begin{abstract}
Background: To compare pregnancy outcomes in growth-restricted fetuses retaining normal umbilical artery doppler flow and the outcomes of pregnancies with end-diastolic velocity diminished or severely reduced/absent.

Methods: In a prospective observational study, one hundred pregnant women with growth-restricted fetuses were followed with doppler velocimetry of the umbilical artery between weeks 28 and 41 of pregnancy. Outcomes were compared for the normal doppler group (55\%) (Group 1), the low-end diastolic flow group (32\%) (Group 2), and the group with severely reduced or absent end-diastolic velocity waveforms (13\%) (Group 3).

Results: Fetuses with abnormal umbilical flow velocimetry had higher incidence of oligohydramnios (82.2\%). The average birth weight and gestational age at delivery were lower in the abnormal doppler group. Significantly more women with severe reduction/AEDV, 31/45 (68.8\%), underwent caesarean section, with 20 of them (44.4\%) for fetal distress, compared with $17 / 55$ (30.9\%) women in the normal doppler group, with 9 of them (16.4\%) for fetal distress. Also, fetuses with abnormal umbilical artery velocimetry had early delivery at less than 36 weeks of gestation (38.2\% versus $65.85 \%$ ), increased NICU admission (32.7\% versus 80\%), need for PPV (5.5\% versus 40\%), low Apgar score $(9.1 \%$ versus $50.2 \%)$ than those with normal doppler. All the three stillbirths in the study population were in the abnormal doppler group.

Conclusions: Umbilical artery doppler velocimetry helps in differentiating fetus with pathological growth restriction at risk for perinatal complications from small and healthy fetuses.
\end{abstract}

Keywords: Doppler, Intrauterine growth restriction, Perinatal outcome, Umbilical artery velocimetry

\section{INTRODUCTION}

Intrauterine growth restriction could be described as the Cinderella area of fetal medicine. Antenatal care in the developed world places great emphasis on the prediction, detection and treatment of maternal disease and the prevention of the birth of babies with major fetal anomalies.

There is now proof that there is fourfold advantage to the health of the fetus that has been prenatally diagnosed with IUGR and who has, as a consequence, benefited from appropriate surveillance instituted thereafter, as opposed to the outcome for the undiagnosed one.

Intra-uterine growth restriction is a common clinical sign of chronic fetal hypoxemia. When fetal growth retardation is diagnosed during the third trimester of pregnancy, the obstetrician must decide whether the fetus is 'constitutionally' small or small as a consequence of impaired placental perfusion. Doppler waveform analysis helps in distinguishing between constitutional and 
pathological smallness. ${ }^{1}$ Detecting the fetus with pathological growth restriction that is at risk for perinatal complications has been an on-going challenge in obstetrics.

Doppler velocimetry is a rapid non-invasive test that provides valuable information about the hemodynamic situation of the fetus. It is an efficient diagnostic test of fetal jeopardy and helps in the management of high-risk pregnancy.

There is significant association between the umbilical arterial doppler waveform analysis and clinical outcome. awareness of an increased, doppler-determined umbilical artery resistance is associated with a reduction in perinatal morbidity and mortality in populations at high risk for adverse perinatal outcomes. ${ }^{2}$ Umbilical artery doppler defines this high-risk subgroup among fetuses diagnosed as SGA. ${ }^{2,3}$

Objectives of this study were;

- To evaluate the role of umbilical artery doppler waveform analysis in growth restricted fetuses

- To study the pregnancy outcomes in growth restricted fetuses with normal umbilical artery velocimetry, low-end diastolic umbilical flow, and absent or reversed diastolic flow waveforms.

\section{METHODS}

The study population consisted of 100 women who had singleton pregnancies with small for gestational age (SGA) fetuses. These women either attended the antenatal clinics with us or were referred from the peripheral hospitals in view of IUGR over a period of two years (August 2017 to August 2019).

\section{Inclusion criteria}

- Singleton pregnancy

- Presence of IUGR fetus

- Gestational age $>28$ weeks

- With Any of the following risk factors:

$>\mathrm{H} / \mathrm{O}$ any previous perinatal death

$>$ Chronic hypertension/gestational hypertension

$>$ Long standing diabetes mellitus

$>$ Autoimmune disorders

$>$ Thrombophiliacs (e.g., APLA associated)

$>$ Previous bad obstetric history.

\section{Exclusion criteria}

- Anomalous or dysmorphic fetuses.

The pregnancies were dated by the combination of last menstrual period and first trimester dating scan. The diagnosis of IUGR was made clinically and confirmed subsequently on ultrasound when the fetal abdominal circumference was less than 2SD (standard deviation) from mean value. A detailed anomaly scan was performed on all fetuses and dysmorphic foetuses were excluded from the study.

A fetal anatomy scan and a biometry were both performed for every patient before the doppler examination. The fetal anatomy scan excluded congenital anomalies and the fetal biometry included biparietal diameter (BPD), head circumference (HC), abdominal circumference (AC) and femur length (FL). Fetal weight was estimated according to the Hadlock et al, formula, which uses FL, AC and BPD. Amniotic fluid volume, which was semi quantitatively assessed, oligohydramnios was considered if $\mathrm{AFI}<5$.

All women included in the study were subjected to umbilical artery doppler measurements in addition to growth parameter, liquor and placental grading. Pulsed wave doppler ultrasound examination of the umbilical artery was performed using colour doppler (GE $700 \mathrm{MR}$ with $3.5 \mathrm{MHz}$ curvilinear transducer). The umbilical artery was identified and flow velocity waveforms were obtained from free-floating loop of cord. Recordings were accepted for analysis only after a clear steady state was obtained for at least two consecutive pulsatile waveforms. No waveforms were recorded during periods of fetal breathing and body movements. The systolicdiastolic (S/D) ratio, resistance index (RI) and pulsatility index (PI) was determined for any waveform and an absence of end-diastolic velocity was noted. The angle between the ultrasound beam and the direction of the blood flow was less than $35^{\circ}$.

For the purpose of analysis, the study population was distributed into two groups- a normal doppler group (Group 1) and an abnormal doppler group. Abnormal doppler group was subdivided into diminished end diastolic flow group (Group II), and an absent or reversed diastolic group (Group III).

Doppler examinations were repeated weekly or biweekly according to the severity of the reduction of the end diastolic flow in the umbilical artery. Patients with S/D ratio equal to or more than three and those with absent diastolic or reversed diastolic flow were admitted for further evaluation and delivery. Conservative treatment that was offered to the patients in the hospital with low end diastolic velocimetry consisted of bed rest, daily fetal movement count, non-stress test. Steroids were administered as single dose to women between 28 and 34 weeks of gestation to enhance fetal lung maturity.

\section{Decision to deliver was taken in situations as}

- $\quad$ Gestation age of 37 weeks

- Absent end diastolic flow, reversed end diastolic flow

- Abnormal fetal heart rate pattern

- Worsening of maternal condition e.g. pre-eclampsia

- $\quad$ Severe IUGR with amniotic fluid index (AFI) $<5$. 
Cervical priming was done with Foleys bulb. Induction of labor was performed with oxytocin in those planned for vaginal delivery. A group of women with associated obstetric indications were scheduled for elective caesarean section. Those developing fetal distress during labor were delivered by emergency caesarean section.

\section{Outcome data collected were}

- Gestational age at birth

- Birth weight

- $\quad$ APGAR scores

- Admission to neonatal intensive care unit

- Need for positive pressure ventilation and neonatal mortality.

\section{Statistical analysis}

The results were expressed as mean \pm SD for continuous data and as number and percentage for categorical data. Unpaired test was used to compare the means of two groups. ANOVA ' $F$ ' test was used for multiple group comparison (birth weight). Categorical data was analysed by chi-square test. For all the tests, a P-value of 0.05 or less was considered as statistically significant. For statistical analysis, SPSS version -16 software was used.

\section{RESULTS}

Maternal, fetal and perinatal characteristics are presented in Table 1. Fifty-five fetuses (55\%) had normal umbilical artery waveforms, thirty-two (32\%) fetuses had diminished end-diastolic flow, and thirteen fetuses (13\%) had severe reduction absent or reversal of end diastolic flow.

Considering maternal characteristics, thirty three of fortyfive $(73.3 \%)$ in abnormal doppler group were hypertensive compared to eighteen of fifty-five $(32.7 \%)$ in normal doppler group. Oligohydramnios was present in thirty seven of forty-five $(82.2 \%)$ women with abnormal doppler group, whereas it was thirteen of fifty-five $(23.6 \%)$ women in normal doppler group (Table 2).

Table 1: Maternal, fetal and perinatal characteristics of the study population $(n=100)$.

\begin{tabular}{|c|c|c|}
\hline Characteristics & Number (n) & Percentage $(\%)$ \\
\hline Hypertensive disorder in pregnancy & 51 & $51 \%$ \\
\hline \multicolumn{3}{|l|}{ Amniotic fluid volume } \\
\hline Oligohydramnios & 50 & $50 \%$ \\
\hline Normal amniotic fluid & 50 & $50 \%$ \\
\hline \multicolumn{3}{|l|}{ Doppler assessment } \\
\hline Normal umbilical artery velocity waveform & 55 & $55 \%$ \\
\hline Diminished umbilical artery end-diastolic velocity & 32 & $32 \%$ \\
\hline Severe reduction absent end-diastolic velocity & 13 & $13 \%$ \\
\hline \multicolumn{3}{|l|}{ Labor } \\
\hline Spontaneous onset & 62 & $62 \%$ \\
\hline Induction & 24 & $24 \%$ \\
\hline Elective cesarean section & 3 & $3 \%$ \\
\hline \multicolumn{3}{|l|}{ Delivery } \\
\hline Spontaneous vaginal delivery & 52 & $52 \%$ \\
\hline Cesarean section & 45 & $45 \%$ \\
\hline \multicolumn{3}{|l|}{ Indication for cesarean section } \\
\hline Abnormal fetal heart rate trace & 29 & $29 \%$ \\
\hline Other & 19 & $19 \%$ \\
\hline \multicolumn{3}{|l|}{ Neonatal characteristics } \\
\hline Perinatal deaths & 14 & $14 \%$ \\
\hline Apgar at birth $<7$ at birth & 24 & $24 \%$ \\
\hline Admission to neonatal intensive care unit & 54 & $54 \%$ \\
\hline Need for positive-pressure ventilation & 21 & $21 \%$ \\
\hline
\end{tabular}

Intrapartum abnormal fetal heart tracing is significantly more for fetuses in the abnormal doppler group (44.4\%) than for fetuses in the normal doppler group (16.4\%). Significantly more women with severe reduction/AEDV, 31 of $45(68.8 \%)$, underwent caesarean section, with 20 of them $(44.4 \%)$ for fetal distress, compared with 17 of $55(30.9 \%)$ women in the normal doppler group, with 9 of them (16.4\%) for fetal distress. Increased incidence of caesarean section is found in patients with abnormal umbilical artery doppler study (68.8\% versus $30.9 \%)$ (Table 3). 
Table 2: Maternal characteristics in abnormal doppler group and normal doppler group.

\begin{tabular}{|c|c|c|c|c|}
\hline \multirow[t]{2}{*}{ Characteristics } & \multirow{2}{*}{$\begin{array}{l}\text { Abnormal doppler } \\
\text { Group }(\mathrm{n}=\mathbf{4 5}) \\
\text { n }(\%)\end{array}$} & \multirow{2}{*}{$\begin{array}{l}\text { Normal doppler } \\
(\mathrm{n}=55) \\
\mathbf{n}(\%)\end{array}$} & \multicolumn{2}{|c|}{ Statistical significance } \\
\hline & & & $x^{2}$ & $\mathbf{P}$ \\
\hline Hypertensive disorder & $33(73.3)$ & $18(32.7)$ & 16.33 & $<0.001$ \\
\hline Oligohydramnios & $37(82.2)$ & $13(23.6)$ & 33.9 & $<0.001$ \\
\hline
\end{tabular}

$x^{2}$ Test.

Table 3: Labor outcome in abnormal doppler group and normal doppler group.

\begin{tabular}{|c|c|c|c|c|}
\hline \multirow[t]{2}{*}{ Characteristics } & \multirow{2}{*}{$\begin{array}{l}\text { Abnormal doppler } \\
\text { Group }(n=45) \\
\text { n }(\%)\end{array}$} & \multirow{2}{*}{$\begin{array}{l}\text { Normal doppler } \\
(n=55) \\
\text { n }(\%)\end{array}$} & \multicolumn{2}{|c|}{ Statistical significance } \\
\hline & & & $x^{2}$ & $\mathbf{P}$ \\
\hline Vaginal delivery & $14(31.10)$ & $38(69.1)$ & 14.3 & $<0.001$ \\
\hline Cesarean section (total) & $31(68.8)$ & $17(30.9)$ & 14.3 & $<0.001$ \\
\hline Cesarean section for fetal distress & $20(44.4)$ & $9(16.4)$ & 9.48 & $=0.002$ \\
\hline
\end{tabular}
$x^{2}$ Test.

Table 4: Doppler characteristics in abnormal doppler group and normal doppler group.

\begin{tabular}{|c|c|c|c|c|}
\hline \multirow[t]{2}{*}{ Characteristics } & \multirow{2}{*}{$\begin{array}{l}\text { Abnormal doppler } \\
\text { Group }(n=45) \\
\text { Mean+SD }\end{array}$} & \multirow{2}{*}{$\begin{array}{l}\text { Normal doppler } \\
(\mathrm{n}=55) \\
\text { Mean } \pm \text { SD }\end{array}$} & \multicolumn{2}{|c|}{ Statistical significance } \\
\hline & & & t - value* & $P$ - value \\
\hline UA pulsatility index (PI) & $1.52 \pm 0.18$ & $0.83 \pm 0.12$ & 19.30 & $<0.001, \mathrm{HS}$ \\
\hline UA resistance index (RI) & $0.76 \pm 0.08$ & $0.50 \pm 0.09$ & 13.39 & $<0.001, \mathrm{HS}$ \\
\hline UA S/D ratio & $4.46 \pm 0.76$ & $2.73 \pm 0.24$ & 15.57 & $<0.001, \mathrm{HS}$ \\
\hline
\end{tabular}

Unpaired $t$ test.

Table 5: NICU admission rate and need for PPV in abnormal doppler group and normal doppler group.

\begin{tabular}{|c|c|c|c|c|}
\hline \multirow{2}{*}{ Characteristics } & \multirow{2}{*}{$\begin{array}{l}\text { A bnormal doppler } \\
\text { Group }(\mathrm{n}=\mathbf{4 5}) \\
\mathbf{n}(\%)\end{array}$} & \multirow{2}{*}{$\begin{array}{l}\text { Normal doppler } \\
(\mathbf{n = 5 5 )} \\
\text { n }(\%)\end{array}$} & \multicolumn{2}{|c|}{ Statistical significance } \\
\hline & & & $x^{2}$ & $\mathbf{P}$ \\
\hline NICU admissions & $36(80)$ & $18(32.7)$ & 22.3 & $<0.001$ \\
\hline Need for PPV & $18(40.0)$ & $3(5.5)$ & 17.8 & $<0.001$ \\
\hline
\end{tabular}

$x^{2}$ Test.

Table 6: Gestational age at delivery and birth weight in abnormal doppler group and normal doppler group.

\begin{tabular}{|c|c|c|c|c|}
\hline \multirow[t]{2}{*}{ Characteristics } & \multirow{2}{*}{$\begin{array}{l}\text { Abnormal doppler } \\
\text { Group }(\mathbf{n = 4 5}) \\
\text { Mean } \pm \text { SD }\end{array}$} & \multirow{2}{*}{$\begin{array}{l}\text { Normal doppler } \\
(n=55) \\
\text { Mean } \pm \text { SD }\end{array}$} & \multicolumn{2}{|c|}{ Statistical significance } \\
\hline & & & t - value* & $P$ - value \\
\hline Gestational age at delivery (weeks) & $35.8 \pm 2.2$ & $37.1 \pm 1.9$ & 2.96 & $0.004, \mathrm{HS}$ \\
\hline Birth weight (g) & $1700 \pm 350$ & $1950 \pm 310$ & 3.80 & $<0.001, \mathrm{HS}$ \\
\hline
\end{tabular}

Unpaired t test.

The mean doppler indices for normal and abnormal doppler groups were $0.83 \pm 0.12$ and $1.52 \pm 0.18(\mathrm{PI})$, $0.50 \pm 0.09$ and $0.76 \pm 0.08(\mathrm{RI}), 2.73 \pm 0.24$ and $4.46 \pm 0.76$ (S/D ratio) respectively (Table 4$)$.

Out of 55 cases in the normal doppler group, 18 newborns $(32.7 \%)$ required NICU admission. Three newborns of $18(5.5 \%)$ admitted in NICU required PPV. whereas 36 of $45(80 \%)$ new-borns in the abnormal doppler group, required NICU admission. Of the thirtysix, 18 of them (40\%) required PPV (Table 5).

The mean gestational age at delivery is $35.8 \pm 2.2$ for fetuses in the abnormal doppler group whereas it is $37.1 \pm 1.9$ for fetuses in the normal doppler group. The mean birth weight is $1.70 \mathrm{~g} \pm 0.35 \mathrm{SD}$ for fetuses in the abnormal doppler group and $1.95 \mathrm{~g} \pm 0.31 \mathrm{SD}$ for those in the normal doppler group (Table 6). Neonatal outcome in the three groups are summarised in Table 7. 
Table 7: Neonatal outcome with umbilical artery doppler velocimetry in the three groups.

\begin{tabular}{|llllll|}
\hline Characteristic & $\begin{array}{l}\text { Normal doppler } \\
(\mathbf{n = 5 5}) \\
\text { Group I, N }(\%)\end{array}$ & $\begin{array}{l}\text { Low EDF } \\
(\mathbf{n = 3 2}) \\
\text { Group II, N (\%) }\end{array}$ & $\begin{array}{l}\text { ADF/RDF } \\
(\mathbf{n = 1 3}) \\
\text { Group III, N (\%) }\end{array}$ & \multicolumn{2}{l|}{$\begin{array}{l}\text { Chi-square test } \\
\text { P - value }\end{array}$} \\
\hline Delivery <36 weeks & $21(38.2)$ & $20(62.5)$ & $9(69.2)$ & 7.00 & $0.03, \mathrm{~S}$ \\
\hline Live/still birth & $55 / 0$ & $31 / 1(3.1)$ & $11 / 2(15.4)$ & 8.55 & $0.01, \mathrm{~S}$ \\
\hline Average birth weight* & $1.95 \pm 0.31$ & $1.76 \pm 0.33$ & $1.54 \pm 0.37$ & $\mathrm{~F}=9.63^{* *}$ & $<0.001, \mathrm{HS}$ \\
\hline Apgar <7 at birth & $5(9.1)$ & $10(31.2)$ & $9(69.2)$ & 33.7 & $<0.001, \mathrm{HS}$ \\
\hline NICU admission & $18(32.7)$ & $25(78.1)$ & $11(84.6)$ & 36.1 & $<0.001, \mathrm{HS}$ \\
\hline $\begin{array}{l}\text { PPV among NICU } \\
\text { admissions }\end{array}$ & $3(5.5)$ & $10(31.2)$ & $8(61.5)$ & 34.1 & $<0.001, \mathrm{HS}$ \\
\hline Neonatal deaths & $1(1.8)$ & $6(18.8)$ & $4(30.8)$ & 11.88 & $0.003, \mathrm{~S}$ \\
\hline $\begin{array}{l}\text { Discharged in good } \\
\text { condition }\end{array}$ & $54(98.2)$ & $25(78.1)$ & $7(53.8)$ & 19.59 & $<0.001, \mathrm{HS}$ \\
\hline
\end{tabular}

$\mathrm{P}<0.05, \mathrm{P}<0.01$ : Significant; $\mathrm{P}<0.001$ : Highly Significant; **ANOVA F test; * Values are expressed as mean \pm SD.

Fetuses in the abnormal umbilical artery doppler group have early delivery (at less than 36 weeks of gestation) $(38.2 \%$ versus $65.85 \%)$, increased NICU admission (32.7\% versus $80 \%)$, need for PPV (5.5\% versus $40 \%)$ and low APGAR score $(9.1 \%$ versus $50.2 \%)$ than those with normal doppler (Figure 1).

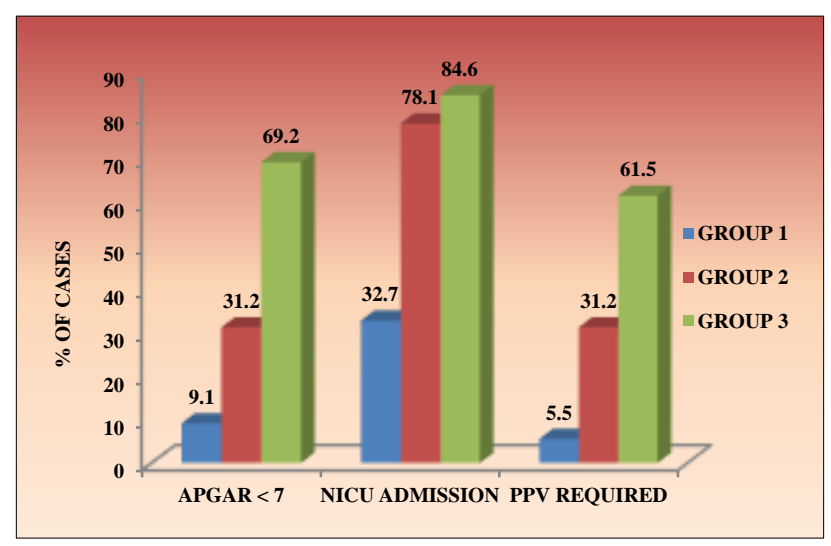

Figure 1: Neonatal outcome in three groups.

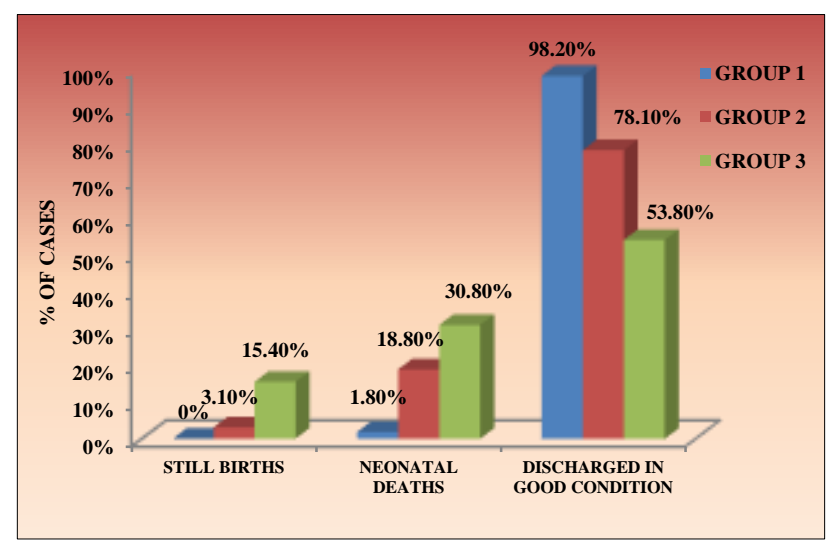

Figure 2: Stillbirths, neonatal deaths $(\%)$ in three groups.
Perinatal mortality is highest in the absent/ reversed end diastolic flow group. There was one stillbirth in group 2 and two stillbirths in group 3 (abnormal doppler group), whereas there was no stillbirth in the normal doppler group. The number of neonatal deaths were 1 (1.8\%), 6 $(18.8 \%)$ and $4(30.8 \%)$ in group 1,2 and 3 respectively (Figure 2).

\section{DISCUSSION}

The pregnancies most likely to be benefitted from the use of umbilical artery velocimetry are those with the diagnosis of intrauterine growth retardation (IUGR) whether as an idiopathic process or in presence of gestational hypertension. ${ }^{4}$ Screening a low-risk or unselected population by umbilical artery Doppler, however, does not reduce perinatal mortality or morbidity. 5,6

Westergaard HB et al, re-examined the reported trials on doppler ultrasound velocimetry in order to define those populations that can truly benefit from its use. In these high-risk pregnancies, application of doppler technology can reduce the number of perinatal deaths. ${ }^{7}$ Hence, one of our inclusion criteria was the presence of intrauterine growth retardation in our patients at examination.

Also, in our study, thirty three of forty-five $(73.3 \%)$ in abnormal doppler group were hypertensive compared to eighteen of fifty-five (32.7\%) in normal doppler group, thus agreeing with other studies. ${ }^{4,7}$

In current practice, assessment of umbilical artery doppler flow is commonly used to determine the risk of adverse perinatal outcome for a fetus that is SGA. Abnormal umbilical artery doppler flow identifies a subgroup of SGA fetuses that are at higher risk for adverse perinatal outcome. 
In our study, it has been shown that perinatal morbidity and mortality were significantly greater in IUGR fetuses with abnormal umbilical artery doppler studies than in those with normal doppler studies. The results of our study show that fetuses with abnormal umbilical artery velocimetry have early delivery (at less than 36 weeks of gestation $(38.2 \%$ versus $65.85 \%)$, increased NICU admission (32.7\% versus $80 \%)$, need for PPV $(5.5 \%$ versus $40 \%)$, low apgar score $(9.1 \%$ versus $50.2 \%)$ than those with normal doppler. Various workers have noticed in fetuses with abnormal umbilical artery doppler velocimetry, a similar poor perinatal outcome..$^{8-10}$

A growth restricted fetus is at an increased risk of perinatal morbidity and mortality. The definition of adverse perinatal outcomes varies in different studies. Diverse end points are used, including major outcomes such as perinatal death, neurological complications (major intracranial haemorrhage, periventricular leucomalacia), and necrotizing enterocoloitis, as well as minor outcomes such as caesarean section for fetal distress, low 5-minute Apgar scores and admission to NICU. Often in few studies, major outcomes are combined with minor outcomes to achieve statistical power. Such is the situation in our study where we have analysed only the immediate perinatal outcome. Some of the infants in our study may have long term morbidity. A neurodevelopmental follow up has not been done to confirm such long-term morbidity.

Baschat AA and Weiner $\mathrm{CP}$, have suggested that antenatal surveillance may be unnecessary in fetuses with suspected IUGR if the UA S/D ratio and amniotic fluid volume are normal, because the complications that occur for these fetuses are intrapartum. ${ }^{11}$ It is reasonable to assume that decreased uteroplacental perfusion during uterine contractions is likely to further jeopardize gaseous exchange in fetuses with pre-existing abnormal umbilical artery velocimetry.

Also, in our study, significantly more women with severe reduction/AEDV, 31 of $45 \quad(68.8 \%)$, underwent Caesarean section, with 20 of them $(44.4 \%)$ for fetal distress, compared with 17 of $55(30.9 \%)$ women in the normal doppler group, with 9 of them $(16.4 \%)$ for fetal distress. Nine of $55(16.4 \%)$ foetuses with normal doppler had an abnormal fetal heart rate tracing, whereas twenty of $45(44.4 \%)$ foetuses with abnormal doppler had abnormal fetal heart tracing before or during labor.

Increased incidence of cesarean section was found in patients with abnormal umbilical artery doppler study ( $31 \%$ versus $17 \%)$. This was in consonance with the findings reported by other authors. ${ }^{2}$

Both open and blind prospective studies have shown that doppler velocimetry gives earlier warning of impending asphyxia than the conventional non-stress test. ${ }^{12}$ Doppler velocimetry also allows more precisely targeted prenatal monitoring and obstetric interventions than cardiotocography. ${ }^{13}$

Abnormal UA velocity waveforms are often detected at early gestational ages when delivery may result in iatrogenic prematurity. The use of doppler velocimetry and cardiotocography, preferably combined with biophysical profile testing, may result in the prolongation of gestational age and an acceptable fetal outcome. Similar findings have been reported by others., ${ }^{414}$

In our study group, the umbilical artery PI in the normal doppler group is 0.83 and in the abnormal doppler group is 1.52. This is comparable to the study done by Deshmukh A et al, who found that PI of umbilical artery was 1.345 in the abnormal doppler group and 0.954 in the normal doppler group. ${ }^{10}$

The mean birth weight is $1.70 \mathrm{~g} \pm 0.35 \mathrm{SD}$ for fetuses in the abnormal doppler group and $1.95 \mathrm{~g} \pm 0.31 \mathrm{SD}$ for those in the normal doppler group. There is a significant decrease in PI of umbilical artery as birth weight increases, the birth weight being higher in the normal doppler group and lowest in the absent/ reversed end diastolic flow group. This is in accordance with Fleischer et al, who demonstrated that those fetuses with lower birth weight $\left(<25^{\text {th }}\right.$ percentile $)$ had higher placental vascular resistance than those with higher birth weight $\left(>25^{\text {th }}\right.$ percentile $) .{ }^{15}$

The mean gestational age at delivery is $35.8 \pm 2.2$ for fetuses in the abnormal doppler group whereas it is $37.1 \pm 1.9$ for fetuses in the normal doppler group.

In our study, newborn with increased SD ratio groups, the AEDF and REDF groups have delivered significantly more preterm compared with the normal doppler group (medians 35.8 weeks versus medians 37.1 weeks, respectively, $\mathrm{P}=0.004$ ) and have lower birthweight (medians $1700 \mathrm{~g}$ versus medians $1950 \mathrm{~g}$, respectively, $\mathrm{P}$ $<0.001)$. This result is comparable to the study done by Shand AW et al. ${ }^{16}$

A possible criticism of our study is the fact that the confounding effects of birth weight, as well as gestational age at delivery were not controlled for.

In a large study of neonatal outcome in relation to umbilical artery doppler findings by Trudinger et al, babies were grouped by gestational age at delivery, and those with abnormal umbilical artery doppler studies spent significantly longer in the neonatal intensive care unit. $^{2}$ In a study of the role of umbilical artery doppler to predict adverse perinatal outcome in women with preeclampsia, Yoon et al, reported, that when gestational age at birth and pre-eclampsia were controlled for, an abnormal umbilical artery doppler study was still a significant independent predictor of adverse perinatal outcome. ${ }^{17}$ 
Conversely, in a recent retrospective cohort study by Shand AW et al, gestational age was a significant risk factor for perinatal mortality and morbidity. ${ }^{16}$ There was no significant association between abnormality of umbilical artery blood flow, perinatal morbidity, perinatal mortality and neurodevelopmental disability after correction for gestational age. One of the strengths of this study is a high rate of neurodevelopmental follow-up for those infants with abnormal UA doppler studies. But this study is limited by its size and retrospective nature. Numbers were too small (119 infants) to evaluate subgroups such as a birth weight centile, birth weight and/or gestation under which a neonate was unlikely to survive or to survive severely disabled.

In a study of McCowanet al when birth weight and gestational age at delivery were controlled for, abnormal umbilical artery doppler status is not an independent predictor of new-born nursery admission or hypoglycaemia. ${ }^{18}$ They conclude abnormal umbilical artery doppler studies reflect earlier onset and more severe growth restriction and are not independently associated with newborn morbidity. Small for gestational age babies with normal doppler studies have a high rate of newborn nursery admission and malnutrition at birth and are not all just normal small babies. Conversely, in a work of Verganiet al. found that in his cohort of fetal growth restricted cases delivered at or beyond 34 weeks gestation with abnormal umbilical artery velocimetry, it independently predicted the likelihood of admission to the NICU for reasons other than low birthweight alone. ${ }^{8}$

A recent work by Figueras $\mathrm{F}$ et al, agrees that abnormal umbilical artery doppler flow identifies a subgroup of SGA fetuses that are at higher risk for adverse perinatal outcome. ${ }^{19}$ While their study was able to confirm this, they also found that a normal umbilical artery doppler provided false reassurance in most cases referred for antenatal investigation if the diagnosis of SGA is established by customized centiles. They argue that normal antenatal umbilical artery doppler cannot be taken as an indicator of low risk in pregnancies where the fetus is SGA according to customized percentiles. This current study shows that cases that are SGA by an individually adjusted standard are at increased risk of adverse outcome regardless of the result of umbilical artery doppler. But they do agree that umbilical artery doppler defines a subgroup with the highest risk among fetuses diagnosed as SGA.

Perinatal mortality was highest in the absent/ reversed end diastolic flow group. Two still births and 4 (30.8\%) neonatal deaths occurred in this group compared to one stillbirth and 7 neonatal deaths in the normal doppler group. Various studies also suggest that in the most extreme waveform abnormality, there is REDF or AEDF which is considered a very ominous sign of placental compromise and is associated with high perinatal mortality rates. Hence incorporation of umbilical artery doppler waveform analysis into management protocols for intrauterine growth restricted fetuses significantly can decrease perinatal mortality.

Though there are controversies between studies regarding the diagnostic efficacy of doppler in the perinatal outcome of IUGR fetuses, all of them agree on the fact that Fetuses that are SGA with abnormal UA doppler studies remain at significant risk of perinatal death, perinatal morbidity and long-term neurodevelopmental disability, associated with their increased risk of preterm birth.

Gestational age, birth weight, birth weight centiles and gender all impact on survival. Parents should be counselled as to the likely short-term and long-term outcomes of a preterm pregnancy. Growth restriction adds to the complexity of counselling parents about the risks of extreme prematurity.

A study by Draper et al, produced gestation- and birth weight-specific survival rates from 24 weeks of gestation, taking into account factors such as fetal sex, ethnicity and singleton or twin. ${ }^{20}$ Use of these tables, rather than ones based on gestation or estimated birth weight alone, is likely to lead to be more accurate estimation of survival. The EPICURE study produced data on developmental disability for extremely preterm infants. Although the data were not specific to growth-restricted infants, they have provided useful information on morbidity when extremely premature delivery is considered. ${ }^{21}$

Thus, the results of our present study have clearly demonstrated the efficacy of doppler in predicting the fetal outcome. Our interpretation is in consonance with a review by Maulik D et al, which agrees that antepartum fetal surveillance with doppler ultrasound of umbilical artery has shown significant diagnostic efficacy in identifying fetal compromise in pregnancies complicated with intra uterine growth restriction (IUGR). ${ }^{22}$ Its effectiveness in decreasing perinatal mortality has been shown by randomized clinical trials. This test is the only antepartum fetal test that has shown this level of effectiveness and should be the standard of practice in managing IUGR. Umbilical artery doppler evaluation of pregnancies with suspected IUGR has been shown to significantly reduce inductions of labor, caesarean deliveries, and perinatal deaths number needed to treat without increasing the rate of unnecessary interventions. Umbilical artery doppler evaluation of the fetus with suspected IUGR can help differentiate the hypoxic growth-restricted fetus from the non-hypoxic small fetus, and thereby reduce perinatal mortality, and unnecessary interventions. So, we are of the opinion that umbilical artery doppler studies should be done for all the patients with IUGR.

\section{CONCLUSION}

The results of our study show that fetuses with abnormal umbilical artery velocimetry have early delivery (at less 
than 36 weeks of gestation), increased NICU admission, need for PPV and low APGAR score than those with normal Doppler. Also, Perinatal mortality was highest in the absent/ reversed end diastolic flow group.

Our study underlines the existence of a strict correlation between umbilical artery Doppler velocimetry and an increased incidence of perinatal complications in IUGR fetuses. Thus, our study concludes that fetal outcome can be well correlated to umbilical artery flow waveforms. Hence, we are of the opinion that umbilical artery doppler studies should be done for all the patients with IUGR.

Since we have analysed only the immediate perinatal outcome in our study, larger follow up studies are required to confirm the same. Our study also noted that, fetuses with increased S/D ratio groups, the AEDF and REDF groups have delivered significantly more preterm compared with the normal doppler group and have lower birth weight. This suggests that the gestational age of the patient at the time of delivery and the birth weight of the newborn also influences the neonatal outcome. So, these factors are equally important and should be taken into consideration while deciding the neonatal outcome. Larger studies controlled for these factors are required before coming to a definite conclusion regarding the diagnostic efficacy of umbilical artery doppler velocimetry in the perinatal outcome of intrauterine growth restricted fetuses.

\section{Funding: No funding sources}

Conflict of interest: None declared

Ethical approval: The study was approved by the Institutional Ethics Committee

\section{REFERENCES}

1. Romero Bobrow CS, Soothill PW. Fetal growth velocity: a cautionary tale. Lancet. 1999;353:1460.

2. Trudinger BJ, Cook CM, Giles WB, Ng S, Fong E, Connelly A, et al. Fetal umbilical artery velocity waveforms and subsequent neonatal outcome. Br J Obstet Gynaecol. 1991;98:378-84.

3. Neilson JP, Alfirevic Z. Doppler ultrasound for fetal assessment in high risk pregnancies. Cochrane Database Syst Rev. 2000;CD000073.

4. American College of Obstetricians and Gynecologists. ACOG Committee opinion. Utility of antepartum umbilical artery Doppler velocimetry in intrauterine growth restriction. 1997:188.

5. Bricker L, Neilson JP. Routine doppler ultrasound in pregnancy. Cochrane Database Syst Rev. 2000; CD001450.

6. Goffinet F, Paris-Llado J, Nisand I, Breart G. Umbilical artery Doppler velocimetry in unselected and low-risk pregnancies: a review of randomised controlled trials. $\mathrm{Br} \mathrm{J}$ Obstet Gynaecol. 1997; 104:425-30.

7. Westergaard HB, Langhoff-Roos J, Lingman G, Marsál K, Kreiner S. A critical appraisal of the use of umbilical artery Doppler ultrasound in high-risk pregnancies: use of meta-analyses in evidence-based obstetrics. Ultrasound Obstet Gynecol. 2001;17:46676.

8. Vergani P, Andreotti C, Roncaglia N, Zani G, Pozzi E, Pezzullo JC, et al. Doppler predictors of adverse neonatal outcome in the growth restricted fetus at 34 weeks' gestation or beyond. Am J Obstet Gynecol. 2003;189(4):1007-11.

9. Arora D, Desai SK, Sheth PN, Kania P. Significance of umbilical artery velocimetry in perinatal outcome of growth restricted fetuses. J Obstet Gynecol India. 2005;55:138-43.

10. Deshmukh A, Soni N, Gokhale S. Significance of umbilical artery Doppler velocimetry in the perinatal outcome of growth restricted fetuses. J Obstet Gynecol India. 2010;60:38-43.

11. Baschat AA, Weiner CP. Umbilical artery Doppler screening for detection of the small fetus in need of antepartum surveillance. Am J Obstet Gynecol. 2000;182:154-8.

12. Malcus $\mathrm{P}$, van Beek E, Marsal K. Umblical artery velocimetry and non-stress test in monitoring highrisk pregnancies: a comparative longitudinal study. Ultrasound Obstet Gynecol. 1991;1:1-7.

13. Almstrom H, Axelsson O, Cnattingius S, Ekman G, Maesel A, Ulmsten U, et al. Comparison of umbilical artery velocimetry and cardiotocography for surveillance of small-for-gestational-age fetuses. Lancet. 1992;340:936-40.

14. Divon MY, Girz BA, Lieblich R, Langer O. Clinical management of the fetus with markedly diminished umbilical artery end-diastolic flow. Am J Obstet Gynecol. 1989;161:1523.

15. Fleischer A, Schulman H, Farmakides G. Umbilical artery velocity waveforms and intrauterine growth retardation. Am J Obstet Gynecol. 1985;151:502-5.

16. Shand AW, Hornbuckle J, Nathan E, Dickinson JE, French NP. Small for gestational age preterm infants and relationship of abnormal umbilical artery Doppler blood flow to perinatal mortality and neuro developmental outcomes. Aus New Zealand J Obstet Gynaecol. 2009;49:52-8.

17. Yoon BH, Lee CM, Kim SW. An abnormal umbilical artery waveform: a strong and independent predictor of adverse perinatal outcome in patients with preeclampsia. Am J Obstet Gynecol. 1994;171:713-21.

18. McCowan KME. Umbilical artery Doppler studies in small for gestational age babies reflect disease severity . Br J Obstet Gynaecol. 2000;107:916-25.

19. Figueras F, Eixarch E, Gratacos E, Gardosi J. Predictiveness of antenatal umbilical artery Doppler for adverse pregnancy outcome in small forgestational-age babies according to customised birth weight centiles: population-based study. Br J Obstet Gynaecol. 2008;115:590-4.

20. Draper ES, Manktelow B, Field DJ, James D. Prediction of survival for preterm births by weight 
and gestational age: retrospective population-based study. BMJ. 1999;319:1093-7.

21. Wood NS, Marlow N, Costeloe K, Gibson AT, Wilkinson AR. Neurologic and developmental disability after extremely preterm birth. EPICURE Study Group. N Engl J Med. 2000;343:378-84.

22. Maulik D, Mundy D, Heitmann E, Maulik D. Umbilical artery Doppler in the assessment of fetal growth restriction. Clinics Perinatol. 2011;38(1):6582 .
Cite this article as: Sumathi R, Rodrigo MR. A prospective study on the role of umbilical artery doppler velocimetry in the perinatal outcome of growth restricted fetuses. Int J Reprod Contracept Obstet Gynecol 2019;8:4930-8. 